\title{
Learning Style Changes And Their Relationship To Critical Thinking Skills
}

C. Siriopoulos, (siriopoulos@upatras.gr), University of Patras, Greece Gerasimos Pomonis, (gpomonis@upatras.gr), University of Patras, Greece

\begin{abstract}
This study reports on the results of a research on learning styles and critical thinking skills of sixty eight postgraduate students of Master's Level Business Education Programs. These students have participated in both phases of our research. In the first phase, carried out in spring 2005, Kolb's Learning Style Inventory (LSI v.3) was the basis of the administered questionnaire and in the second phase, carried our in winter 2005 - 06, the LSI v.3 and the California Critical Thinking Skills Test (CCTST) were the basis of the administered questionnaire. Results show that the prevailing learning style types are the 'assimilating' and the 'converging' ones. Between the first and the second phase students have become more balanced learners. This balanced learning development relates to both 'Concrete - Abstract' and 'Active - Reflective' dimensions of the learning process and this latter dimension correlates significantly with students' critical thinking skills on all scales of the used instrument.
\end{abstract}

\section{INTRODUCTION AND LITERATURE REVIEW}

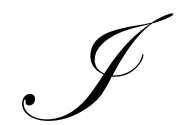

$\mathrm{t}$ is a commonplace in education literature that not everyone learns in the same way. There have been developed several instruments to assess adult learning styles while many researchers and instructors look for influential teaching methods and techniques to enhance student learning. Information and communication technology advances have changed the way Master's level Business Education Courses can be delivered. For instance, some of the Top MBA programs deliver their core finance courses by devoting more teaching time on case studies than lectures, some of them by devoting all of the time on lectures, and most of them by devoting more time on lectures and less time on case studies (Womack, 2001). Instructors aware of the developments in learning theory try to implement problem-based learning, collaborative learning, or, in general, teaching methods that require active student engagement in the learning process and there is also a need for teaching to lead to the development of student critical thinking skills. Teaching-and-learning is an interactive process where, neither should all the teaching be done by the teacher, nor should all the learning be done by the student (Boyce, 2001). Taking into account that teaching styles differ, as well as learning styles differ, the outcome of this interaction may be greater if instructors implement student-oriented teaching strategies that lead students to adopt broader learning strategies. A basic step towards the selection and implementation by instructors of teaching strategies to better serve the aforementioned interaction is the identification of student learning styles. Even though students may be unaware of their learning styles, there are certain course delivery method preferences for each learning style (Duff, 1997; Kolb, 2000), while there is also an impact on faculty-student relationships (Whipple and Moberg, 2000). Taking into account that there are also age, gender, and occupational implications of different learning styles (Kolb, 2000; Honey and Mumford, 2000; Nawrocki, David and Christine, 2005), it is important for instructors to produce an analysis of students' learning styles that can lead to effective teaching and learning strategies, enhance learning and develop critical thinking skills.

There is a general consensus in the research literature that students in higher education exhibit a number of different approaches to learning, i.e. there are different student learning styles. Researchers and instructors use several instruments to identify and interpret the implications of learning styles in a wide range of purposes, as learning styles 
represent an important aspect of teaching and learning effectiveness. Besides, there are several instruments to measure student critical thinking skills.

Duff (1997) searches for the relationship between student learning styles and the prediction of their academic achievement in accounting courses by using Honey and Mumfords's Learning Styles Questionnaire and Schmeck's Inventory of Learning Processes. He reports that, to his surprise, the predictive validity of both instruments is not supported by his data, contrary to prior research findings. This discrepancy may be owed to cultural, occupational, and subject specialism differences, or to instructional methods selection.

Kreber (1998) considers the relationship between self-directed learning, critical thinking, and psychological type and argues that Kolb's experiential learning theory and his four different learning mode preferences may be used to assist students to develop intuition and logical thinking and become self-directed lifelong learners.

Whipple and Moberg (2000) use a questionnaire that combined 35 scale items they devised with Kolb's Learning Style Inventory to identify students' expectations of relationships with faculty and find significant correlations between students' learning styles and the relationships they want from their instructors.

Heffler (2001) utilizes Kolb's Learning Style Inventory to identify students' learning style differences for age and gender. He reports that analysis of his data indicates non-significant correlations between learning styles and age, significant correlations between some learning modes and gender and non-significant for some others, while a hierarchical five-cluster analysis showed homogenous groups with different learning styles.

Wessel and Williams (2004) utilize Kolb's Learning Style Inventory, the California Critical Thinking Disposition Inventory (CCTDI) and the California Critical Thinking Skills Test (CCTST) to identify the relationship between learning styles and critical thinking disposition and ability. Their research data analysis indicates positive correlations between critical thinking disposition and ability and the learning style of 'convergers'.

Barnes et al. (2004) utilize Kolb's Learning Style Inventory to examine the nexus between student learning styles and their preference of course delivery methods in an online MBA course. Their research data show most students' learning styles mainly fall in two of Kolb's four learning styles and indicate different delivery methods preference, albeit all of them do not like PowerPoint presentations.

Adler et al. (2004) utilize Kolb's Learning Style Inventory to find if the use of teacher-led and student-led case presentations in an intermediate cost and management accounting course has any impact on students' learning styles. The pre-test was followed by teacher-led (Harvard style) introductory cases, then student-led cases were presented and discussed, and finally the post-test was completed. They find student learning style improvements towards a more balanced learning style for those with active involvement, but not in all areas for all students.

Siriopoulos and Pomonis (forthcoming) use a questionnaire based on Kolb's LSI to identify student learning differences in Master's programs that imply chances and risks for career selection by students and find that students may run the risk of selecting an inappropriate program relative to careers implied by their learning styles.

Duff (1998) comments on the relationship of objective tests, the process of learning to learn, and learning styles, Cano-Garcia and Hughes (2000) analyze the interrelationship of student learning and thinking styles on academic achievement, Desmarais and Ritchie (2001) consider the designing of instructional methods suitable for different learning styles, Loo (2002) considers the distribution of student learning styles and the selection of business majors, and Duff (2004) examines the role of cognitive learning styles in accounting education for the development of learning competences, just to mention a few more literature review items to exhibit the diversity and the importance of student learning style assessment and utilization.

The purpose of this paper is to examine if students develop more balanced learning styles during their Master's level business education programs studies, as well as to examine the interrelationship between learning styles and critical thinking skills. The remainder of this paper is arranged as follows. In the next section we present the 
methodology of the research. This is followed by the presentation of the results and this by the discussion of the results. In the final section we conclude the paper with some notes for further research.

\section{METHODOLOGY}

\section{Sample Collection And Synthesis}

In March and April 2005 during the first phase of our research a questionnaire containing 35 questions and which was based on Kolb's Learning Style Inventory v.3 (LSI v.3) as regards learning style assessment was administered to 288 students in Master's level business education programs of six major Greek Universities. In December 2005 and January 2006 during the second phase of our research a questionnaire containing 74 questions based on Kolb's LSI v.3 and the California Critical Thinking Skills Test (CCTST) was administered to 586 students in Master's level business education programs in seven major Greek Universities. Questionnaires were anonymous but in both phases participants were assigned with a code that helped for checking for errors and omissions and feedback. Among these students there are sixty eight students in several different classes of these programs that have completed the questionnaires in both phases of the research. These students comprise our sample that is selected by chance, as some students have graduated, others have continued their studies to the next year of studies, and we administered the questionnaires during certain class sessions that were different between the two phases of the research. The age of our sample's participants is shown in Table 1. The prevalent age interval is 24 to 29 years that comprises the $63.2 \%$ of the sample. It has to be noticed that Greek students typically finish their higher education four year studies at 22 to 23 years of age. In our sample there are some students of the Hellenic Open University that accepts students of bigger age and that is why there are 40+ aged students. In Table 2 we present the gender dispersion of the sample to various study disciplines that are commonly found in postgraduate business education programs.

Table 1: Participants' Age

\begin{tabular}{|c|c|c|c|}
\hline \multicolumn{2}{|c|}{} & Frequency & Percent \\
\hline Valid & $<24$ & 8 & 11,8 \\
\hline & $24-29$ & 43 & 63,2 \\
\hline & $30-39$ & 13 & 19,1 \\
\hline & $40+$ & 4 & 5,9 \\
\hline
\end{tabular}

Males comprise the $45.6 \%$ and females the $54.4 \%$ of our sample. This relatively balanced male - female participation does not hold for every individual studies discipline, while there is only one student for each of science (physics), geoponics, and nursing. Although students attending Master's level business education programs possess various degrees, accounting and finance, business administration, public administration, and economics students, taken together as closely related, comprise the $73.5 \%$ of the sample.

\section{Use Of Instruments}

As mentioned above the two questionnaires administered in each of the two phases of our research are based on the LSI v.3 and the CCTST.

LSI v.3

Kolb's LSI v.3 is one of the most well known instruments to measure students' learning styles with numerous applications in research. The LSI is based on Kolb's Experiential Learning Model (Kolb, 1984; Kolb, 2000), which is a simple description of the learning cycle - how experience is translated into concepts, which, in turn, are used as guides in the choice of new experiences. The learning cycle consists of four stages: Concrete Experience (CE), Reflective Observation (RO), Abstract Conceptualization (AC), and Active Experimentation (AE). The learning style is an individual's unique set of experiences that lead to the development of a preferred style of learning, or 
learning style is simply the way an individual prefers to absorb and incorporate new information. Each learning style type emerges as a combination of two subtractions: subtraction of the value of $\mathrm{CE}$ from the value of $\mathrm{AC}$, which are vertically polar opposites in the Concrete-Abstract Dimension of the learning cycle, and subtraction of the value of RO from the value of AE, which are horizontally polar opposites in the Active-Reflective Dimension of the learning cycle. The first dimension is how students perceive new information or experience, and the second is how they process what they perceive. Combinations of the subtractions result in four learning style types: (1) diverging types, (CE and RO preference), (2) assimilating types, (RO and AC preference), (3) converging types, (AC and AE preference), and (4) accommodating types, (AE and CE preference). These four learning style types are depicted in four consecutive quadrants from upper right to upper left, which are formed by the two intersecting axes depicting the two dimensions of the learning cycle. Kolb $(1984 ; 2000)$ indicates that balanced learners are more effective learners and an effective problem-solver should use all four learning styles in a cyclical fashion. An individual who emphasizes specific components of the learning cycle to the omission of others may be an ineffective critical thinker.

Table 2: Gender And Studies Discipline

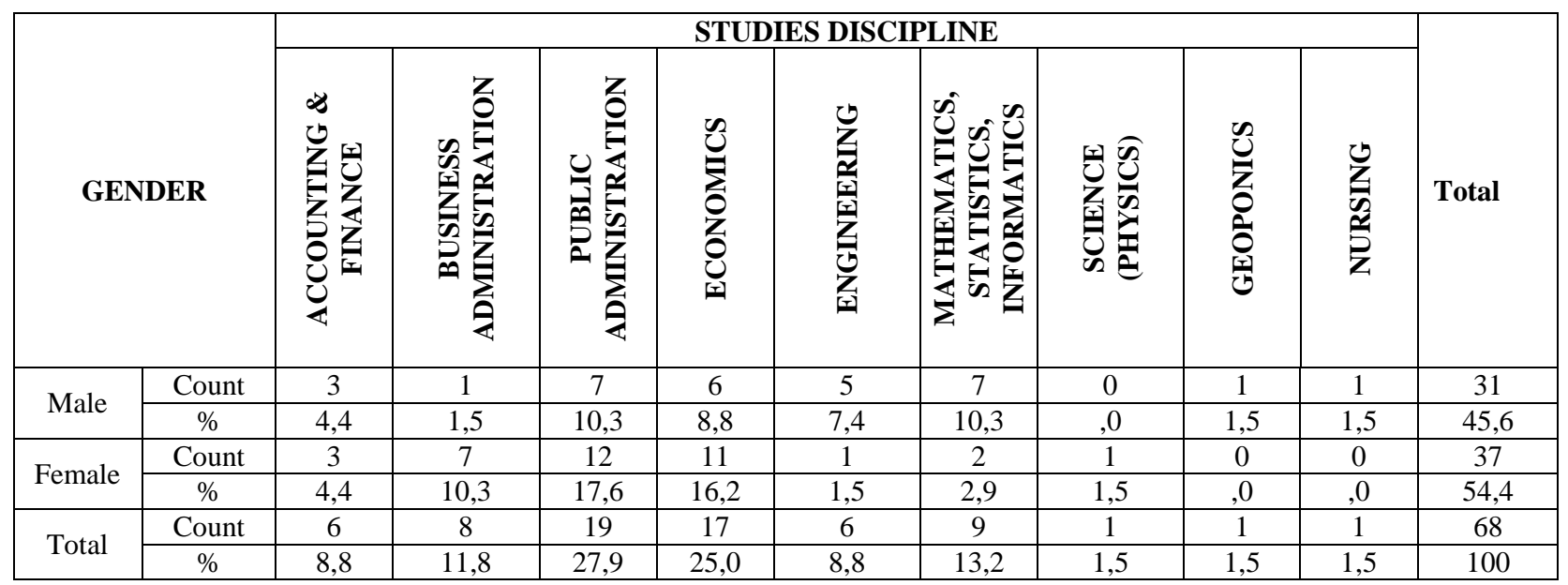

\section{CCTST}

The CCTST was developed and tested to evaluate the skills identified by the Delphi report (American Philosophical Association, 1990). This instrument has 34 multiple-choice questions requiring a range of critical thinking skills such as analyzing the meaning of a sentence, drawing the correct inference from a set of assumptions, or evaluating objections to stated inference. One point is given for each correct answer and, the higher the overall points an individual scores, the higher his/her ability in critical thinking. Gained scores are distributed in five subscales which are induction, deduction, inference, analysis, and evaluation. The results of several studies (Giancarlo and Facione, 2001; Facione et al, 2002) suggest that university education improves critical thinking.

\section{RESULTS}

Between the first and the second phase of our research, at least seven months have elapsed. During this period of time students that have participated in both phases have completed their first year studies, have participated in June 2005 exams, and have proceeded towards completing their winter semester of their second year studies, just before mid-January exams. In Table 3 we present the LSI v.3 scores for both phases, grouped for study discipline, relative to possessed degree. Numbers 1 and 2 following each learning style and type denote scores for first and second research phase respectively. For each study discipline scores are different between the two phases. With the exception of science, geoponics, and nursing categories that comprise only of one student each, the following figures depict mean scores for each category. 
Table 3: Learning Styles And Types Means Per Studies Discipline

\begin{tabular}{|c|c|c|c|c|c|c|c|c|c|c|c|c|c|}
\hline STUDIES DISCIP & INE & $\overrightarrow{\widehat{x}}$ & 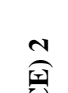 & $\overrightarrow{0}$ & $\hat{0}$ & $\overline{0}$ & $\frac{v}{\partial}$ & $\overrightarrow{\widehat{I}}$ & $\stackrel{\sim}{(1)}$ & 预 & 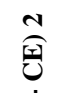 & $\overrightarrow{\widehat{0}}$ & $\stackrel{N}{\hat{\partial}}$ \\
\hline 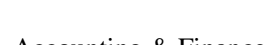 & $\mathrm{N}$ & 6 & 6 & 6 & 6 & 6 & 6 & 6 & 6 & 6 & 6 & 6 & 6 \\
\hline 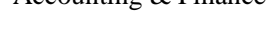 & Mean & 22,8 & 25,7 & 26,8 & 32,2 & 36,2 & 31,8 & 34,2 & 30,3 & 13,3 & 6,1 & 7,3 & $-1,8$ \\
\hline Business & $\mathrm{N}$ & 8 & 8 & 8 & 8 & 8 & 8 & 8 & 8 & 8 & 8 & 8 & 8 \\
\hline Administration & Mean & 18,5 & 19,9 & 34,0 & 32,6 & 30,3 & 31,0 & 37,3 & 36,5 & 11,7 & 11,1 & 3,3 & 3,8 \\
\hline Public Adminictration & $\mathrm{N}$ & 19 & 19 & 19 & 19 & 19 & 19 & 19 & 19 & 19 & 19 & 19 & 19 \\
\hline 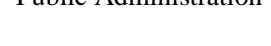 & Mean & 19,2 & 22,6 & 34,1 & 32,4 & 33,2 & 31,2 & 33,5 & 33,8 & 14,0 & 8,5 &,- 5 & 1,4 \\
\hline Economico & $\mathrm{N}$ & 17 & 17 & 17 & 17 & 17 & 17 & 17 & 17 & 17 & 17 & 17 & 17 \\
\hline Lconvints & Mean & 17,6 & 20,5 & 32,9 & 31,3 & 33,0 & 32,1 & 36,5 & 36,1 & 15,4 & 11,6 & 3,6 & 4,8 \\
\hline Enainorino & $\mathrm{N}$ & 6 & 6 & 6 & 6 & 6 & 6 & 6 & 6 & 6 & 6 & 6 & 6 \\
\hline & Mean & 26,5 & 23,8 & 30,2 & 30,7 & 29,3 & 30,2 & 34,0 & 35,3 & 2,8 & 6,3 & 3,8 & 4,6 \\
\hline Mathematics, & $\mathrm{N}$ & 9 & 9 & 9 & 9 & 9 & 9 & 9 & 9 & 9 & 9 & 9 & 9 \\
\hline Statistics, Informatics & Mean & 21,8 & 22,6 & 32,9 & 28,4 & 31,1 & 34,8 & 34,2 & 34,2 & 9,3 & 12,2 & 1,3 & 5,7 \\
\hline (Dh or & $\mathrm{N}$ & 1 & 1 & 1 & 1 & 1 & 1 & 1 & 1 & 1 & 1 & 1 & 1 \\
\hline 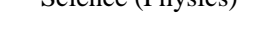 & Mean & 25,0 & 30,0 & 25,0 & 38,0 & 30,0 & 25,0 & 40,0 & 27,0 & 5,0 & $-5,0$ & 15,0 & $-11,0$ \\
\hline Geononice & $\mathrm{N}$ & 1 & 1 & 1 & 1 & 1 & 1 & 1 & 1 & 1 & 1 & 1 & 1 \\
\hline & Mean & 22,0 & 23,0 & 27,0 & 32,0 & 34,0 & 35,0 & 37,0 & 30,0 & 12,0 & 12,0 & 10,0 & $-2,0$ \\
\hline Nursing $>$ & $\mathrm{N}$ & 1 & 1 & 1 & 1 & 1 & 1 & 1 & 1 & 1 & 1 & 1 & 1 \\
\hline & Mean & 15,0 & 19,0 & 30,0 & 30,0 & 38,0 & 40,0 & 37,0 & 31,0 & 23,0 & 21,0 & 7,0 & 1,0 \\
\hline Totol & $\mathrm{N}$ & 68 & 68 & 68 & 68 & 68 & 68 & 68 & 68 & 68 & 68 & 68 & 68 \\
\hline & Mean & 20,1 & 22,2 & 32,3 & 31,5 & 32,5 & 31,9 & 35,1 & 34,4 & 12,4 & 9,7 & 2,7 & 2,9 \\
\hline
\end{tabular}

Figure 1: Accounting And Finance Graduates $1^{\text {st }}$ And $2^{\text {nd }}$ Phase Learning Styles

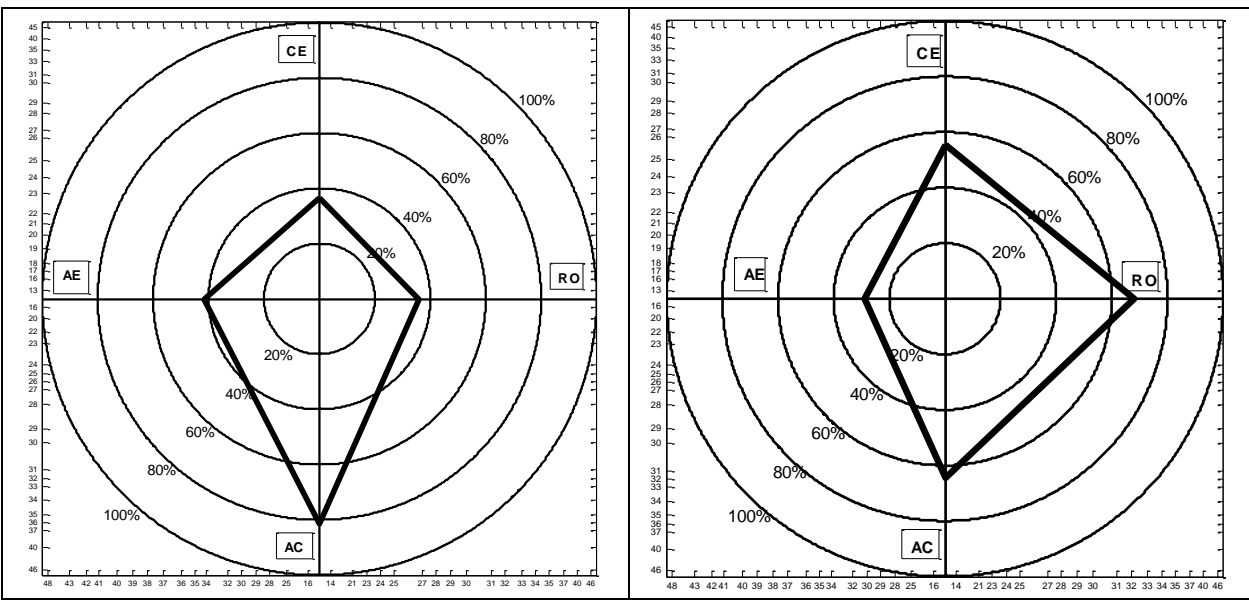


Figure 1 depicts changes in learning styles of accounting and finance graduates. Besides the fact that their prevailing learning styles have changed from 'converging' to 'assimilating', they appear to be more balanced learners, as there is no score showing preference of a certain dimension reaching the $80^{\text {th }}$ percentile, as shown on the left side of the figure.

Figure 2: Business Administration Graduates $1^{\text {st }}$ And $2^{\text {nd }}$ Phase Learning Styles

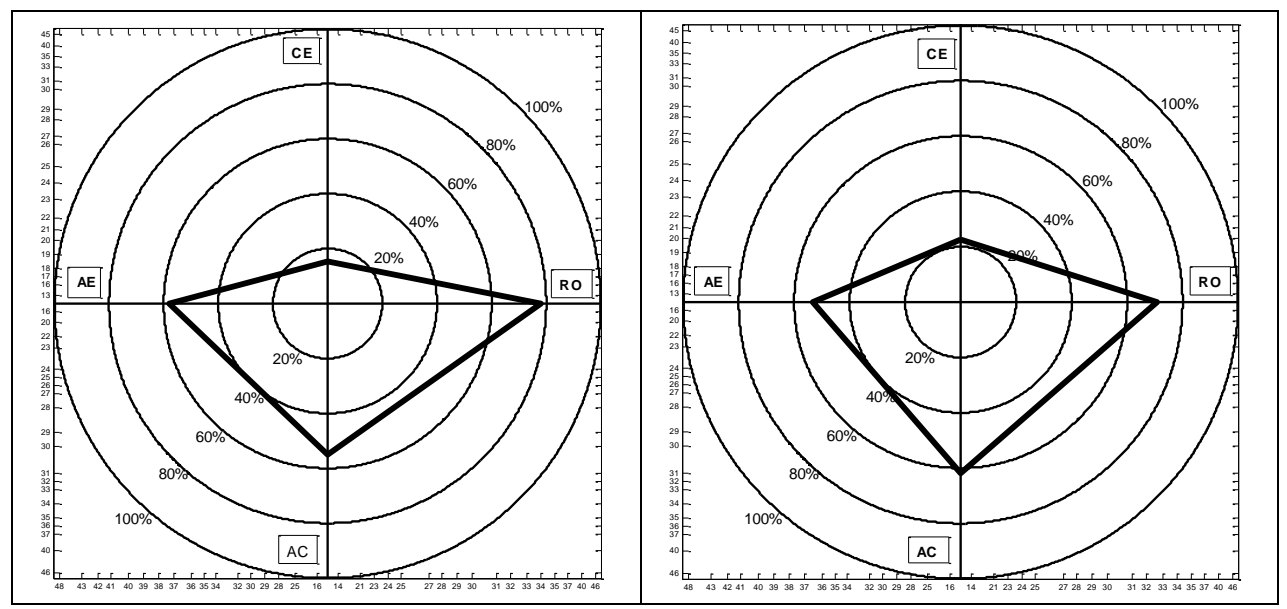

Similar changes hold true for business administration graduates, as shown in figure 2. Their learning style preferences have become more modest and more balanced, although they show low preference towards the CE stage of the learning cycle, which is below the $20^{\text {th }}$ percentile initially and is just over the $20^{\text {th }}$ percentile for the $2^{\text {nd }}$ phase. Figure 3 shows public administration graduates' learning styles. Similarly to business administration graduates, they do not change learning style preferences and they show low preference for the CE stage of the learning cycle, but their preferences become more modest, as their mean RO preference does not touch the $80^{\text {th }}$ percentile and their mean $\mathrm{AC}$ preference just exceeds the $60^{\text {th }}$ percentile, while their CE preference is higher than that of the business administration graduates. Thus, they have become more balanced learners.

Figure 3: Public Administration Graduates $1^{\text {st }}$ And $2^{\text {nd }}$ Phase Learning Styles

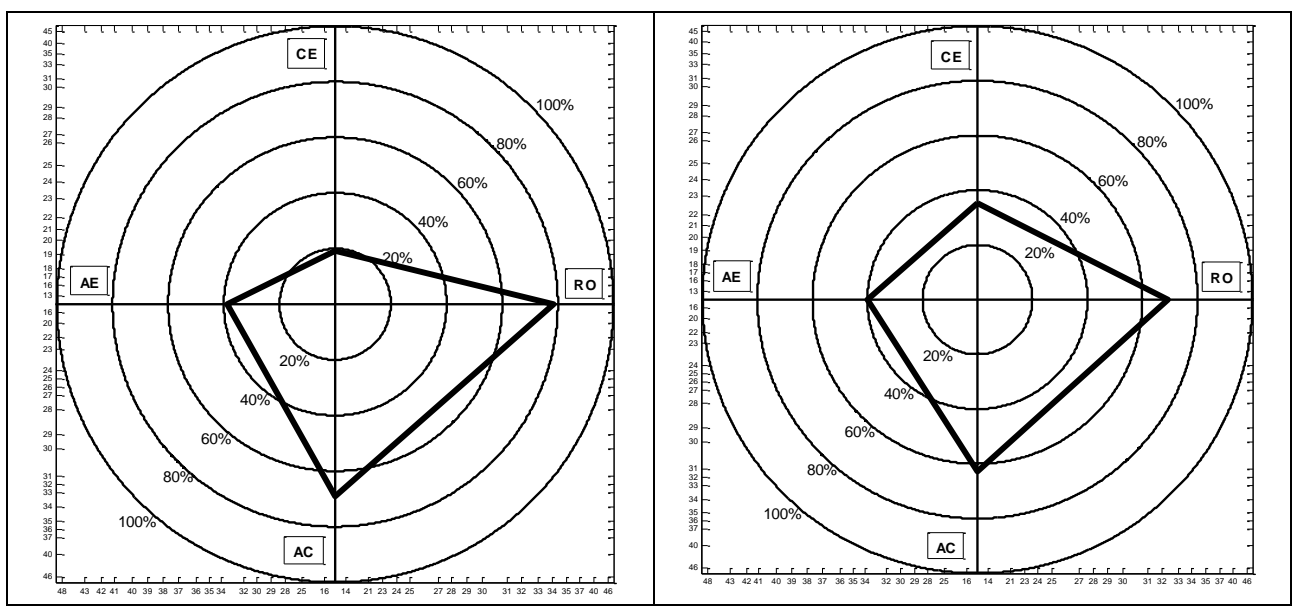


Figure 4 shows economics graduates' learning styles. As in the case of business and public administration graduates, economics graduates have low preference for CE. In fact they show the lowest preference than any of the previous closely related discipline categories, but they, too, develop more balanced preferences.

Figure 4: Economics Graduates $1^{\text {st }}$ And $2^{\text {nd }}$ Phase Learning Styles

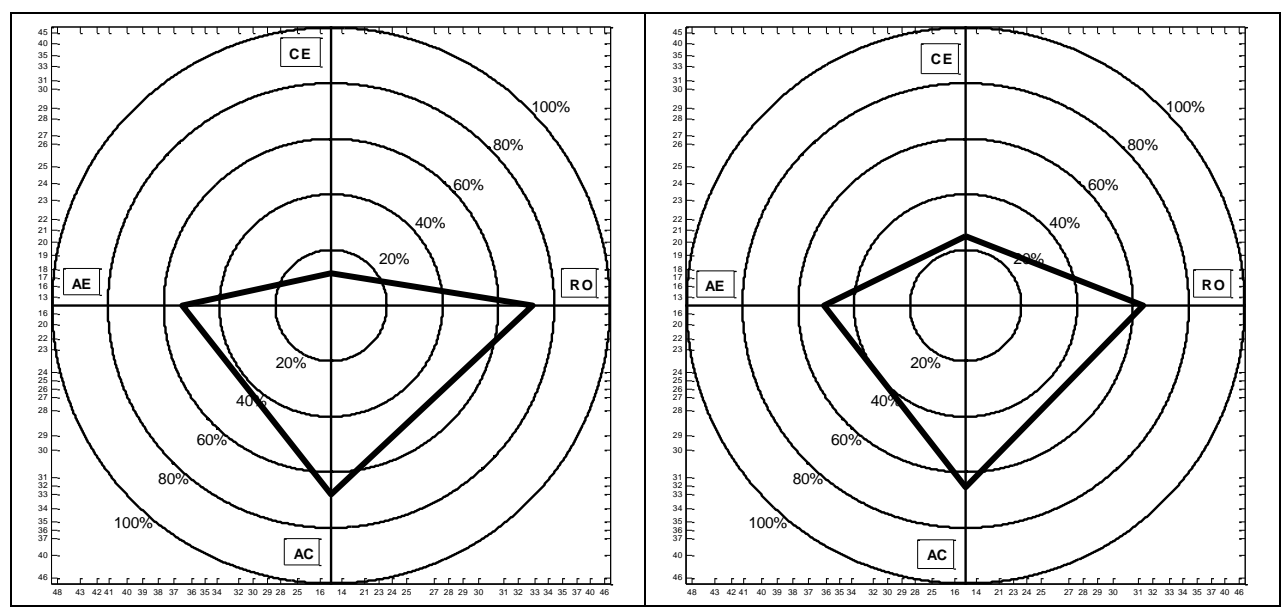

Figure 5: Engineering Graduates $1^{\text {st }}$ And $2^{\text {nd }}$ Phase Learning Styles

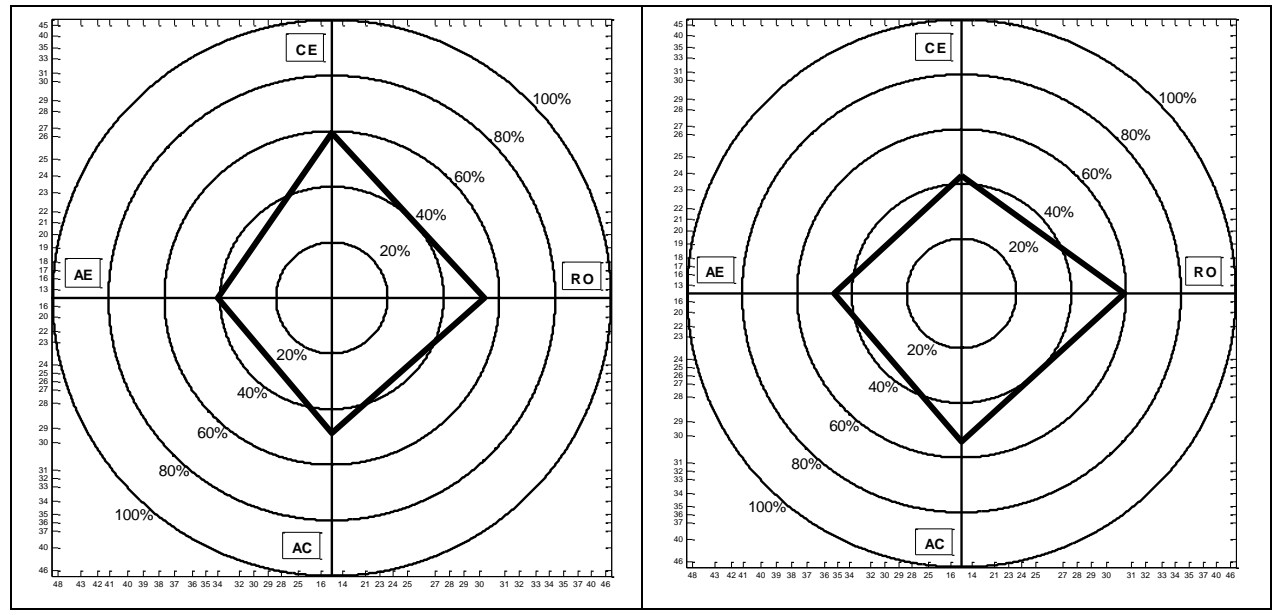

Figure 5 shows engineering graduates' learning styles. This category is different from the previously mentioned ones, which are closely related discipline categories. Engineering graduates show high preference for the $\mathrm{CE}$ stage of the learning cycle, relative to the previous categories, and they appear to have more balanced preferences. In the second phase their preferences change to further balanced ones and in doing so their prevailing 'diverging' learning style changes to the 'assimilating' one.

Figure 6 shows mathematics, statistics, and informatics graduates' learning styles. These graduates initially show a high preference for the RO stage of the learning cycle and in the $2^{\text {nd }}$ phase they change to high preference for the $\mathrm{AC}$ one. In doing so it is not clear that they become more balanced in their preferences. 
Figure 6: Mathematics, Statistics, And Informatics Graduates $1^{\text {st }}$ And $2^{\text {nd }}$ Phase Learning Styles
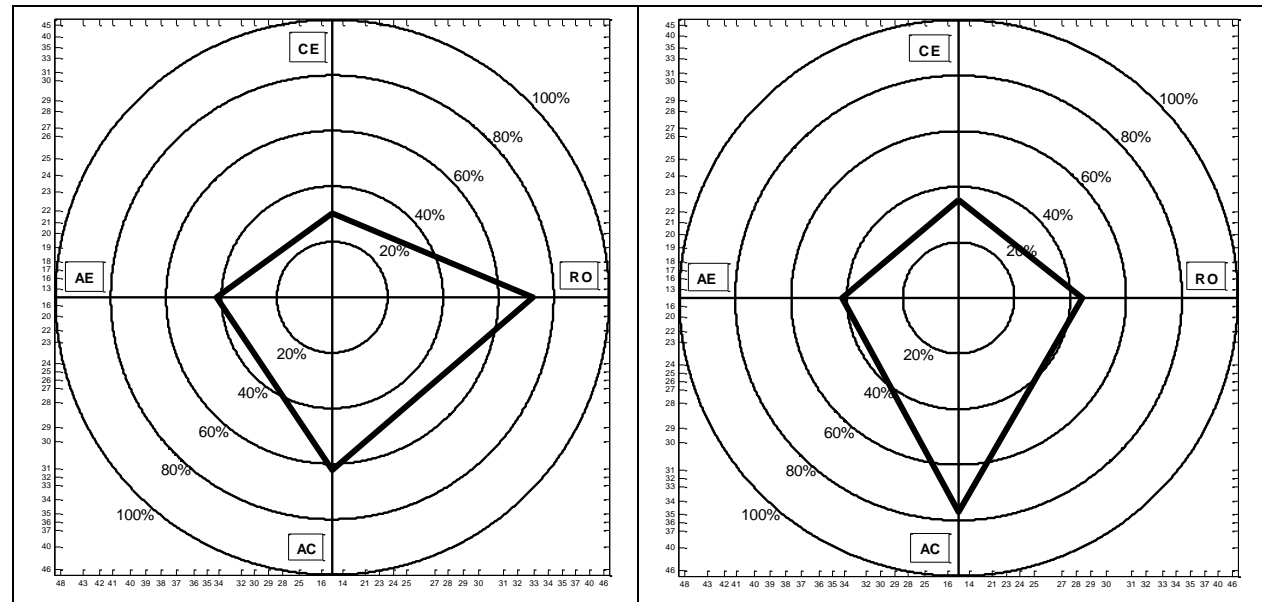

The overall result in learning styles changes is depicted in figure 7 . The development of more balanced learning style preferences for every category previously shown leads to the 'kite' shape of the right side of this figure that shows more balanced preferences relative to the initial ones shown on the left side.

Figure 7: All Study Disciplines $1^{\text {st }}$ And $2^{\text {nd }}$ Phase Learning Styles

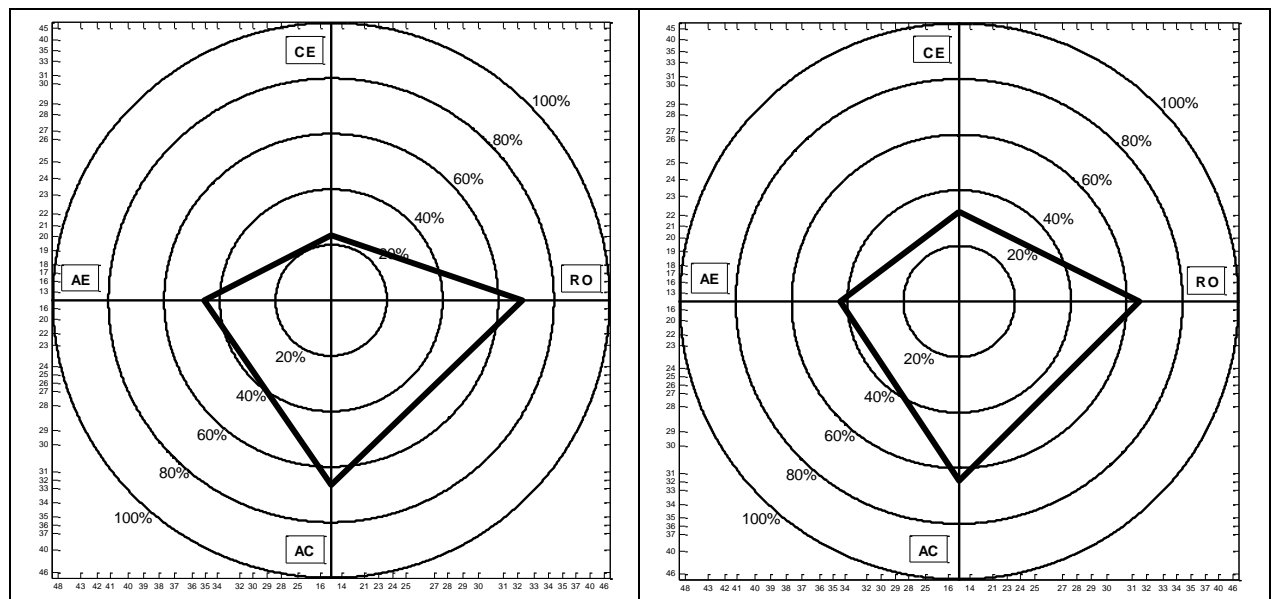

According to Kolb's model, combinations of learning styles lead to the learning style types. If an individual or the mean scores of a group develop to more balanced preferences, this means that no stage of the learning cycle has any particular weighing and the relative combination is close to the intersecting point of the axes. Figure 8 depicts the learning style types for each discipline category for the $1^{\text {st }}$ and the $2^{\text {nd }}$ stage of the research. Accounting and finance graduates' preferences change from 'converging' to 'assimilating' (see legend and main figure 8) and the new point of their combination is a little more close to the intersecting point. Business administration graduates' preferences also move a little to the left and more close to the intersecting point. Public administration graduates' preferences lead to a more evident move towards the intersecting point and the same holds for economics graduates. Engineering graduates' combinations of preferences are close to the intersecting point with a little improvement as they show relatively balanced preferences in both phases. The only group that shows no clear improvement is the mathematics, 
statistics, and informatics graduates group. The overall result is more balanced learning style preferences and this is depicted by the sample data sign movement towards the intersecting point of the axes.

Figure 8: All Disciplines $1^{\text {st }}$ And $2^{\text {nd }}$ Phase Learning Style Types

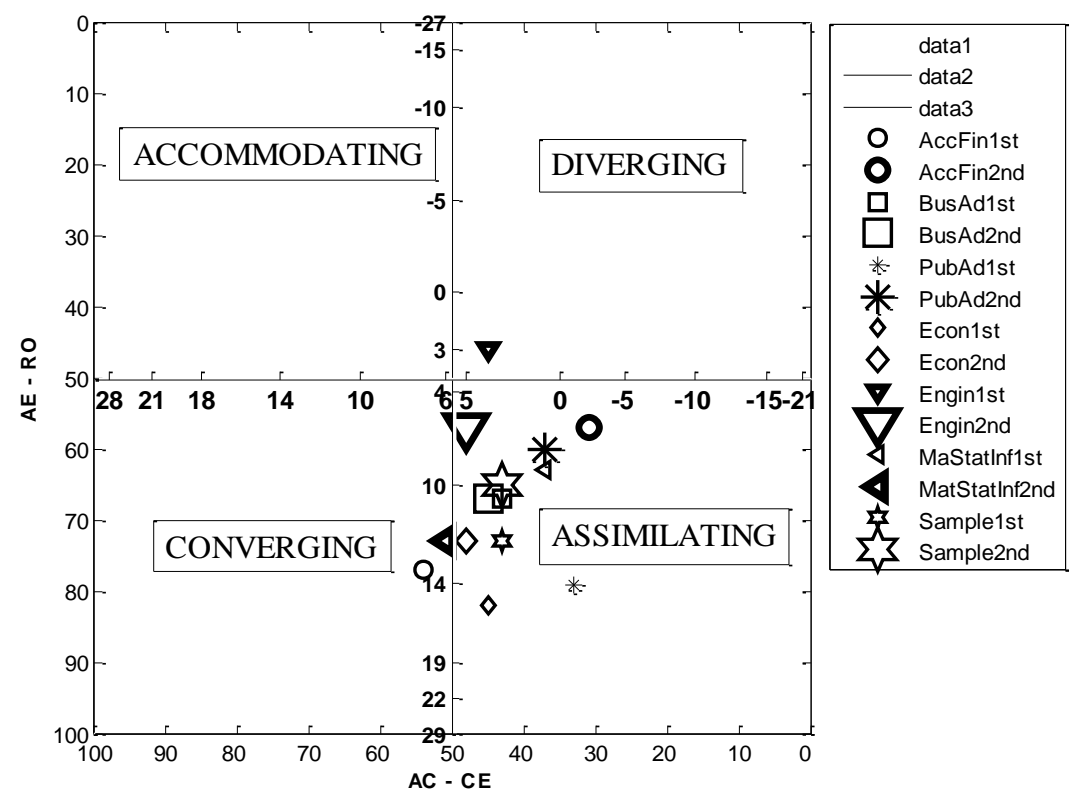

The assessment of student learning styles in the $1^{\text {st }}$ and $2^{\text {nd }}$ phase of this research gives the changes and improvement towards more balanced student learning styles and types. Tables 4 and 5 incorporate these changes. Table 4 shows the student learning style types per study discipline. The prevailing learning style type is the 'assimilating' one representing $52.8 \%$ of the total of 68 students. Second in frequency is the 'converging' one with $34 \%$ of the total. 'Diverging' and 'accommodating' come in $3^{\text {rd }}$ and $4^{\text {th }}$ place with $8.8 \%$ and $4.4 \%$ respectively. In the $2^{\text {nd }}$ phase assessment, as shown in table 5, the 'assimilating' learning style type remains the prevailing one, albeit with a percentage reduced to $48.5 \%$, followed by 'converging' with a percentage reduced to $30.9 \%$, 'diverging' increased to $11.8 \%$, and 'accommodating' increased to $8.8 \%$.

To test if these changes in learning style types give a more clear aspect of the development of more balanced learning styles, we group the participants learning styles and types scores according to their learning style types. Table 6 shows the scores in the $1^{\text {st }}$ and $2^{\text {nd }}$ phase of the research of the participants, grouped for their initial learning style type. Neither do learning styles scores, nor do learning style types scores remain the same between the two phases.

The 'kite' shapes of the learning styles of the participants grouped for their initial learning style types are depicted in figure 9. In all cases the second phase scores produce a more balanced preference in learning styles, but 'diverging' and 'converging' ones show a dramatic improvement in the balancing of learning style preferences. 'Old' and 'new' student learning style types are depicted in figure 10. Small signs represent the first phase learning style types and the bigger ones represent the second phase learning style types. The aforementioned dramatic improvement of the 'divergers' and 'converges' is shown by a bigger movement of the relative signs towards the intersecting point of the axes, relative to 'assimilators' and 'accommodators'. 
Table 4: First Phase Learning Style Types Per Studies Discipline

\begin{tabular}{|c|c|c|c|c|c|c|c|c|c|c|c|}
\hline \multirow{2}{*}{\multicolumn{2}{|c|}{ LEARNING TYPES }} & \multicolumn{9}{|c|}{ STUDIES DISCIPLINE } & \multirow{3}{*}{$\begin{array}{c}\text { Total } \\
\\
\\
6\end{array}$} \\
\hline & & 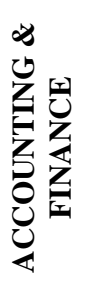 & 鬲 & 光 & $\begin{array}{l}\infty \\
\sum_{0}^{\infty} \\
0 \\
0 \\
0\end{array}$ & 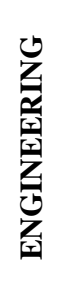 & 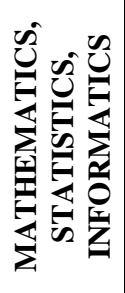 & 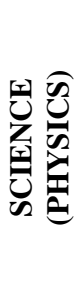 & 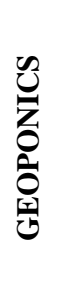 & 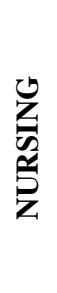 & \\
\hline \multirow{2}{*}{ Diverging } & Count & 0 & 0 & 1 & 0 & 3 & 2 & 0 & 0 & 0 & \\
\hline & $\%$ & 0 & 0 & 1,5 & , 0 & 4,4 & 2,9 & 0 & , 0 & ,0 & 8,8 \\
\hline \multirow{2}{*}{ Assimilating } & Count & 2 & 4 & 14 & 10 & 2 & 4 & 0 & 0 & 0 & 36 \\
\hline & $\%$ & 2,9 & 5,9 & 20,5 & 14,7 & 2,9 & 5,9 & 0 & , 0 & ,0 & 52,8 \\
\hline \multirow{2}{*}{ Converging } & Count & 4 & 4 & 1 & 7 & 1 & 3 & 1 & 1 & 1 & 23 \\
\hline & $\%$ & 5,9 & 5,9 & 1,5 & 10,3 & 1,5 & 4,4 & 1,5 & 1,5 & 1,5 & 34 \\
\hline \multirow{2}{*}{ Accommodating } & Count & 0 & 0 & 3 & 0 & 0 & 0 & 0 & 0 & 0 & 3 \\
\hline & $\%$ & , 0 & , 0 & 4,4 &, 0 & , 0 & , 0 &, 0 & , 0 & , 0 & 4,4 \\
\hline \multirow{2}{*}{ Total } & Count & 6 & 8 & 19 & 17 & 6 & 9 & 1 & 1 & 1 & 68 \\
\hline & $\%$ & 8,8 & 11,8 & 27,9 & 25,0 & 8,8 & 13,2 & 1,5 & 1,5 & 1,5 & 100 \\
\hline
\end{tabular}

Table 5: Second Phase Learning Types Per Studies Discipline

\begin{tabular}{|c|c|c|c|c|c|c|c|c|c|c|c|}
\hline \multirow{2}{*}{\multicolumn{2}{|c|}{ LEARNING TYPES }} & \multicolumn{9}{|c|}{ STUDIES DISCIPLINE } & \multirow{3}{*}{$\begin{array}{c}\text { Total } \\
\\
\\
8\end{array}$} \\
\hline & & 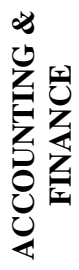 & 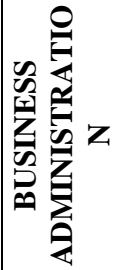 & 总 & 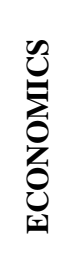 & 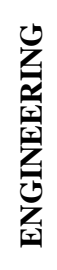 & 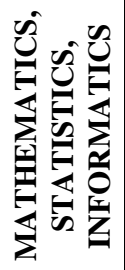 & 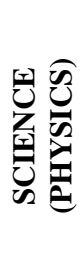 & $\begin{array}{l}0 \\
0 \\
Z \\
0 \\
0 \\
0 \\
0 \\
0 \\
0\end{array}$ & $\begin{array}{l}\text { Z } \\
\text { 泀 } \\
\text { そ }\end{array}$ & \\
\hline \multirow{2}{*}{ Diverging } & Count & 2 & 1 & 1 & 1 & 1 & 1 & 1 & 0 & 0 & \\
\hline & $\%$ & 2,9 & 1,5 & 1,5 & 1,5 & 1,5 & 1,5 & 1,5 & , 0 & , 0 & 11,8 \\
\hline \multirow{2}{*}{ Assimilating } & Count & 3 & 4 & 13 & 7 & 2 & 2 & 0 & 1 & 1 & 33 \\
\hline & $\%$ & 4,4 & 5,9 & 19,1 & 10,3 & 2,9 & 2,9 & ,0 & 1,5 & 1,5 & 48,5 \\
\hline \multirow{2}{*}{ Converging } & Count & 1 & 2 & 2 & 8 & 3 & 5 & 0 & 0 & 0 & 21 \\
\hline & $\%$ & 1,5 & 2,9 & 2,9 & 11,8 & 4,4 & 7,4 &, 0 &, 0 & , 0 & 30,9 \\
\hline \multirow{2}{*}{ Accommodating } & Count & 0 & 1 & 3 & 1 & 0 & 1 & 0 & 0 & 0 & 6 \\
\hline & $\%$ & 0 & 1,5 & 4,4 & 1,5 & 0 & 1,5 & ,0 & ,0 & 0 & 8,8 \\
\hline \multirow{2}{*}{ Total } & Count & 6 & 8 & 19 & 17 & 6 & 9 & 1 & 1 & 1 & 68 \\
\hline & $\%$ & 8,8 & 11,8 & 27,9 & 25,0 & 8,8 & 13,2 & 1,5 & 1,5 & 1,5 & 100 \\
\hline
\end{tabular}


Table 6: Learning Styles And Types Means Grouped For Learning Types

\begin{tabular}{|c|c|c|c|c|c|c|c|c|c|c|c|c|c|}
\hline \multicolumn{2}{|c|}{ LEARNING TYPES } & \multirow{2}{*}{ 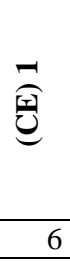 } & \multirow{2}{*}{ 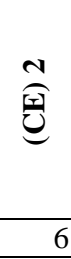 } & \multirow{2}{*}{\begin{tabular}{r}
$\stackrel{\overrightarrow{0}}{a}$ \\
$\quad 6$ \\
\multirow{2}{*}{}
\end{tabular}} & \multirow{2}{*}{$\begin{array}{r}\stackrel{\mathfrak{o}}{\mathscr{\theta}} \\
6\end{array}$} & \multirow{2}{*}{ 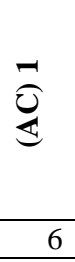 } & \multirow{2}{*}{$\frac{\tilde{U}}{\tilde{U}}$} & \multirow{2}{*}{ 勇 } & \multirow{2}{*}{$\frac{\underset{3}{2}}{2}$} & \multirow{2}{*}{ 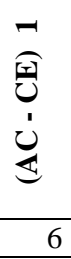 } & \multirow{2}{*}{ 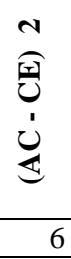 } & \multirow{2}{*}{ 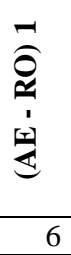 } & \multirow{2}{*}{ 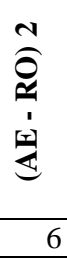 } \\
\hline & $\mathrm{N}$ & & & & & & & & & & & & \\
\hline & Mean & 31,3 & 26,3 & 32,2 & 29,5 & 24,2 & 29,3 & 32,3 & 34,8 & $-7,1$ & 3,0 &, 1 & 5,3 \\
\hline \multirow{2}{*}{ Assimilating } & $\mathrm{N}$ & 36 & 36 & 36 & 36 & 36 & 36 & 36 & 36 & 36 & 36 & 36 & 36 \\
\hline & Mean & 18,3 & 20,6 & 35,8 & 33,0 & 34,4 & 33,2 & 31,6 & 33,3 & 16,0 & 12,5 & $-4,1$ &, 2 \\
\hline \multirow{2}{*}{ Converging } & $\mathrm{N}$ & 23 & 23 & 23 & 23 & 23 & 23 & 23 & 23 & 23 & 23 & 23 & 23 \\
\hline & Mean & 19,0 & 23,1 & 27,7 & 30,0 & 32,9 & 31,5 & 40,4 & 35,4 & 13,9 & 8,3 & 12,8 & 5,4 \\
\hline \multirow{2}{*}{ Accommodating } & $\mathrm{N}$ & 3 & 3 & 3 & 3 & 3 & 3 & 3 & 3 & 3 & 3 & 3 & 3 \\
\hline & Mean & 27,7 & 25,7 & 27,3 & 29,0 & 23,3 & 25,7 & 41,7 & 39,7 & $-4,3$ &, 0 & 14,3 & 10,7 \\
\hline \multirow{2}{*}{ Total } & $\mathrm{N}$ & 68 & 68 & 68 & 68 & 68 & 68 & 68 & 68 & 68 & 68 & 68 & 68 \\
\hline & Mean & 20,1 & 22,2 & 32,3 & 31,5 & 32,5 & 31,9 & 35,1 & 34,4 & 12,4 & 9,8 & 2,8 & 2,9 \\
\hline
\end{tabular}

Figure 9: Learning Styles Grouped For Initial Learning Style Types

Diverging $1^{\text {st }}$ Phase




Accommodating $1^{\mathrm{st}}$ Phase

Figure 10: $1^{\text {st }}$ And $2^{\text {nd }}$ Phase Learning Style Types Grouped For Initial Learning Style Types

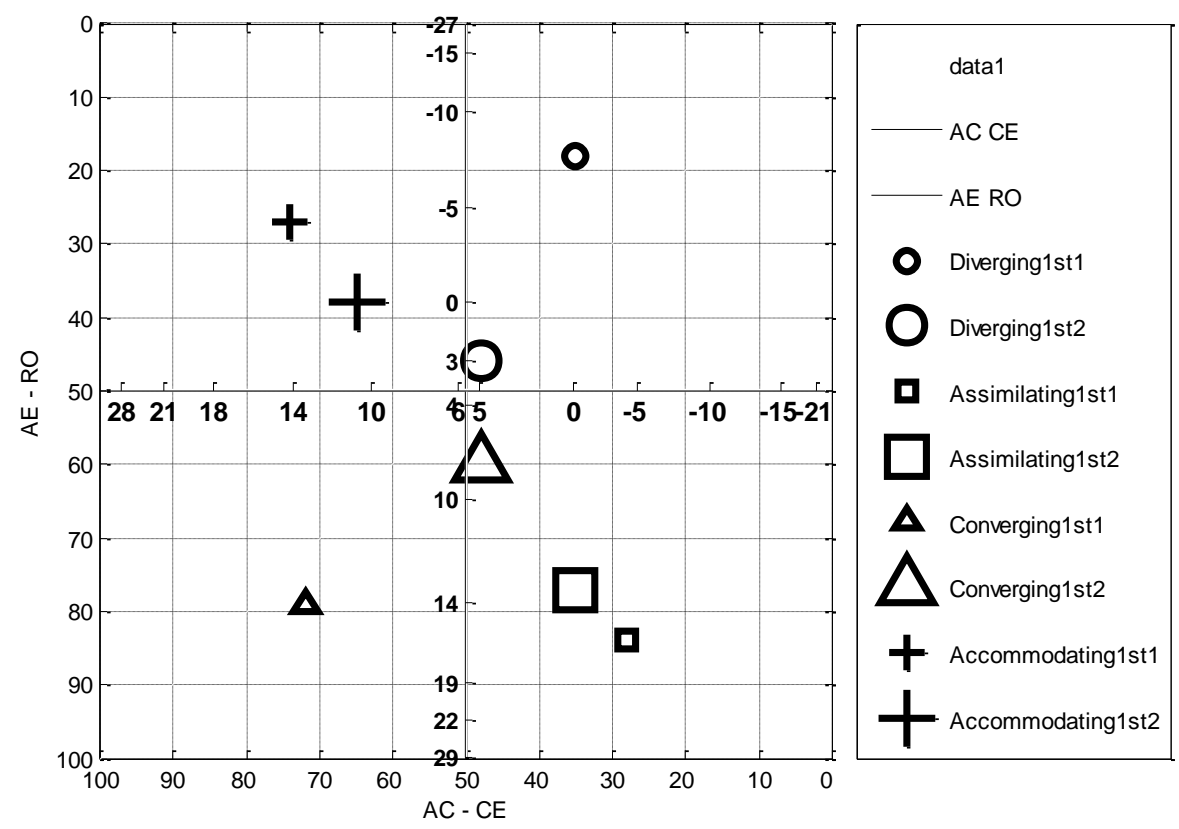

Is this development of more balanced learning styles and types connected in some way with postgraduate student critical thinking skills? Mean scores of all scales of the CCTST grouped for studies disciplines are shown in Table 7. These mean scores are relatively low compared with other research reports (Facione et al, 2002), but there are some noticeable differences between the group means. Not taking into account the science (physics) score, as well as geoponics and nursing, as there is just one student for each, the economics graduates' mean overall score is the highest of all (14.4) with the smaller standard deviation (2.89). In the induction subscale accounting and finance graduates 
score higher than all others (5.83), but with the higher standard deviation (3.43), in the deduction subscale economics graduates score higher (7.52) with the smallest standard deviation (1.87), in the analysis subscale business administration graduates score higher (5.0) with a relatively high standard deviation, in the inference subscale economics graduates score higher (4.94) with a relatively low standard deviation (1.67), and in the evaluation subscale accounting and finance graduates score higher (5.5), but with the highest standard deviation (2.58).

Table 7: Critical Thinking Scales Means Per Studies Discipline

\begin{tabular}{|c|c|c|c|c|c|c|c|}
\hline \multicolumn{2}{|c|}{ STUDIES DISCIPLINE } & \multirow{2}{*}{ 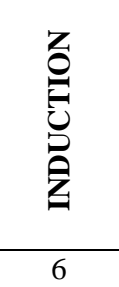 } & \multirow{2}{*}{$\begin{array}{l}Z \\
\varrho \\
0 \\
0 \\
0 \\
0 \\
0 \\
0\end{array}$} & \multirow{2}{*}{$\begin{array}{l}\frac{\infty}{3} \\
\frac{\pi}{3} \\
\frac{\pi}{Z}\end{array}$} & \multirow{2}{*}{ 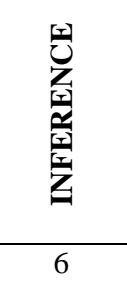 } & \multirow{2}{*}{ 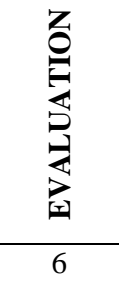 } & \multirow{2}{*}{ 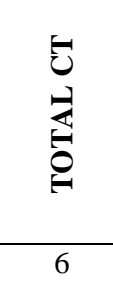 } \\
\hline \multirow{3}{*}{ Accounting \& Finance } & $\mathrm{N}$ & & & & & & \\
\hline & Mean & 5,8333 & 5,5000 & 3,6667 & 3,3333 & 5,5000 & 12,5000 \\
\hline & Std. Dev. & 3,43026 & 2,50998 & 2,25093 & 2,94392 & 2,58844 & 7,23187 \\
\hline \multirow{3}{*}{ Business Administration } & $\mathrm{N}$ & 8 & 8 & 8 & 8 & 8 & 8 \\
\hline & Mean & 4,0000 & 7,0000 & 5,0000 & 4,0000 & 4,0000 & 13,0000 \\
\hline & Std. Dev. & 1,69031 & 2,26779 & 2,07020 & 1,85164 & 1,41421 & 2,92770 \\
\hline \multirow{3}{*}{ Public Administration } & $\mathrm{N}$ & 19 & 19 & 19 & 19 & 19 & 19 \\
\hline & Mean & 4,4737 & 6,2632 & 3,6316 & 4,1579 & 4,2105 & 12,0000 \\
\hline & Std. Dev. & 2,29416 & 2,90291 & 1,94966 & 2,00730 & 2,12339 & 5,46707 \\
\hline \multirow{3}{*}{ Economics } & $\mathrm{N}$ & 17 & 17 & 17 & 17 & 17 & 17 \\
\hline & Mean & 5,2353 & 7,5294 & 4,3529 & 4,9412 & 5,1176 & 14,4118 \\
\hline & Std. Dev. & 1,75105 & 1,87475 & 1,32009 & 1,67595 & 1,16632 & 2,89523 \\
\hline \multirow{3}{*}{ Engineering } & $\mathrm{N}$ & 6 & 6 & 6 & 6 & 6 & 6 \\
\hline & Mean & 4,3333 & 6,1667 & 3,5000 & 3,3333 & 4,8333 & 11,6667 \\
\hline & Std. Dev. & 2,16025 & 2,78687 & 1,51658 & 2,33809 & 1,94079 & 3,82971 \\
\hline \multirow{3}{*}{$\begin{array}{l}\text { Mathematics, Statistics, } \\
\text { Informatics }\end{array}$} & $\mathrm{N}$ & 9 & 9 & 9 & 9 & 9 & 9 \\
\hline & Mean & 5,5556 & 7,1111 & 3,6667 & 4,8889 & 5,1111 & 13,6667 \\
\hline & Std. Dev. & 1,74005 & 2,31541 & 1,80278 & 1,61589 & 1,83333 & 3,60555 \\
\hline \multirow{3}{*}{ Science (Phusics) } & $\mathrm{N}$ & 1 & 1 & 1 & 1 & 1 & 1 \\
\hline & Mean & 7,0000 & 8,0000 & 4,0000 & 5,0000 & 7,0000 & 16,0000 \\
\hline & Std. Dev. & . & 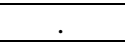 & . & . & . & . \\
\hline \multirow{3}{*}{ Geoponics } & $\mathrm{N}$ & 1 & 1 & 1 & 1 & 1 & 1 \\
\hline & Mean & 4,0000 & 3,0000 & 1,0000 & 3,0000 & 3,0000 & 7,0000 \\
\hline & Std. Dev. &. &. &. &. &. &. \\
\hline \multirow{3}{*}{ Nursing } & $\mathrm{N}$ & 1 & 1 & 1 & 1 & 1 & 1 \\
\hline & Mean & 3,0000 & 7,0000 & 4,0000 & 4,0000 & 4,0000 & 12,0000 \\
\hline & Std. Dev. &. & . & . & . &. & . \\
\hline \multirow{3}{*}{ Total } & $\mathrm{N}$ & 68 & 68 & 68 & 68 & 68 & 68 \\
\hline & Mean & 4,8676 & 6,6912 & 3,9412 & 4,2794 & 4,7206 & 12,9412 \\
\hline & Std. Dev. & 2,12241 & 2,44496 & 1,78620 & 1,96116 & 1,81902 & 4,38070 \\
\hline
\end{tabular}

Another aspect of critical thinking skills scores is given by grouping the participants' scores for their learning style types. Table 8 shows the scores of the participants, grouped for their initial learning style type. Students with 'accommodating' learning style type score higher than all (17.67) with the smallest standard deviation (2.1), albeit they are just three students. These three 'accommodators' score higher than any other group in all critical thinking subscales with low standard deviations, which are the lowest of all other groups for every subscale except for evaluation. Although total sample means and standard deviations remain the same irrespective of the grouping for study discipline or learning style types, this second regrouping of the participants critical thinking skills scores gives 
lower standard deviations which means that this kind of grouping leads to relatively more homogeneous groups. This comes as a different explanation of how students score in critical thinking, according to their learning style types, irrespective of their graduate degree possessed.

Up to this point of analysis of the results, two developments are noticeable. The first is that learning styles and types of the participating students show an improvement towards more balanced learning, as shown by the 'kite' shapes of their learning style preferences and the movement towards the intersecting point of the axes for learning style types. This is more aptly shown by grouping for participants' learning style types. The second is that student critical thinking scores show a better homogeneity if grouped for learning style types. Do these two developments imply any relationship between learning style types and student critical thinking skills? Associations between learning styles and types and critical thinking scales were determined by means of Pearson's and Spearman's correlation coefficients. Out of all of these correlations we have run analyzing data, Table 9 shows those depicting the association between learning style types and critical thinking scales. First research phase scores for (AC-CE) and critical thinking scales are negatively and not statistically significantly correlated, while some of them change sign in the second phase. $(\mathrm{AE}-\mathrm{RO})$ and critical thinking scales are positively correlated in both phases, but correlations are significant for the second phase scores, either at the 0.01 or at the 0.05 levels.

Table 8: Critical Thinking Scales Means Per Learning Style Type

\begin{tabular}{|c|c|c|c|c|c|c|c|}
\hline \multicolumn{2}{|c|}{ LEARNING STYLE TYPES } & ְֶ̆ & 兒 & $\frac{\infty}{\sqrt[n]{2}}$ & 空 & $\stackrel{\varrho}{\underbrace{\complement}}$ & 它 \\
\hline \multirow{3}{*}{ Diverging } & $\mathrm{N}$ & 6 & 6 & 6 & 6 & 6 & 6 \\
\hline & Mean & 5,5000 & 7,1667 & 4,3333 & 4,1667 & 5,3333 & 13,8333 \\
\hline & Std. Deviation & 1,87083 & 2,92689 & 1,96638 & 2,31661 & 1,36626 & 4,66548 \\
\hline \multirow{3}{*}{ Assimilating } & $\mathrm{N}$ & 36 & 36 & 36 & 36 & 36 & 36 \\
\hline & Mean & 4,5000 & 6,1667 & 3,8056 & 4,0833 & 4,3611 & 12,2500 \\
\hline & Std. Deviation & 2,21037 & 2,48998 & 1,86424 & 2,11626 & 1,91465 & 4,63141 \\
\hline \multirow{3}{*}{ Converging } & $\mathrm{N}$ & 23 & 23 & 23 & 23 & 23 & 23 \\
\hline & Mean & 5,0435 & 7,0435 & 3,8261 & 4,4783 & 4,8696 & 13,1739 \\
\hline & Std. Deviation & 2,03332 & 2,16329 & 1,66930 & 1,70213 & 1,65980 & 3,85713 \\
\hline \multirow{3}{*}{ Accommodating } & $\mathrm{N}$ & 3 & 3 & 3 & 3 & 3 & 3 \\
\hline & Mean & 6,6667 & 9,3333 & 5,6667 & 5,3333 & 6,6667 & 17,6667 \\
\hline & Std. Deviation & 1,52753 & 1,15470 &, 57735 & 1,52753 & 1,52753 & 2,08167 \\
\hline \multirow{3}{*}{ Total } & $\mathrm{N}$ & 68 & 68 & 68 & 68 & 68 & 68 \\
\hline & Mean & 4,8676 & 6,6912 & 3,9412 & 4,2794 & 4,7206 & 12,9412 \\
\hline & Std. Deviation & 2,12241 & 2,44496 & 1,78620 & 1,96116 & 1,81902 & 4,38070 \\
\hline
\end{tabular}


Table 9: Critical Thinking Scales And Learning Dimensions Correlation

\begin{tabular}{|c|c|c|c|c|c|c|}
\hline & 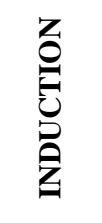 & 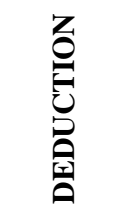 & $\frac{n}{\frac{0}{2}}$ & 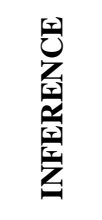 & 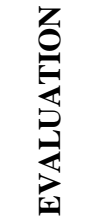 & 苞 \\
\hline \multirow{2}{*}{$(\mathrm{AC}-\mathrm{CE}) 1$} & -.125 & -.185 & -.192 & -.029 & -.124 & -.143 \\
\hline & .308 & .130 & .116 & .816 & .313 & .245 \\
\hline \multirow{2}{*}{$(\mathrm{AC}-\mathrm{CE}) 2$} & .014 & -.050 & .056 & .048 & -.021 & .035 \\
\hline & .910 & .685 & .652 &., 696 & .863 & .774 \\
\hline \multirow{2}{*}{$(\mathrm{AE}-\mathrm{RO}) 1$} & .154 & .138 & .037 & .075 & .164 & .116 \\
\hline & .210 & .260 & .766 & .544 & .182 & .344 \\
\hline \multirow{2}{*}{$(\mathrm{AE}-\mathrm{RO}) 2$} & $.248(*)$ & $.338(* *)$ & $.243(*)$ & $.274(*)$ & $.251(*)$ & $.326(* *)$ \\
\hline & .041 & .005 & .046 & .024 & .039 & .007 \\
\hline
\end{tabular}

** Correlation is significant at the 0.01 level (2-tailed). * Correlation is significant at the 0.05 level (2-tailed).

\section{DISCUSSION}

Prior research has confirmed that learning styles change and researchers call for further work in the area (Marriott, 2002). This study confirms changes in learning styles at a postgraduate level. The change is clearer when student scores for their learning preferences are grouped for their learning style types. Furthermore, this study identifies that this change moves towards a certain direction, which implies that students become more balanced learners (Kolb, 2000). This result implies that students get involved in all four stages of Kolb's learning cycle and this, if effectively directed through the use of certain teaching methods and problem-based orientation of graduate and postgraduate programs, may foster students' critical thinking ability (Kreber, 2001). Critical thinking ability is higher when there are positive correlations between the LSI and the CCTST scores, as this indicates that individuals who prefer learning by active experimentation (greater AE-RO) are more likely to be inquisitive and self-confident in their critical thinking, while those who prefer learning by abstract conceptualization (greater AC-CE) tend to be more analytical and have better critical thinking skills (Wessel and Williams, 2004). This means that individuals with this scoring are classified as 'convergers' and in this study 23 students representing $33.8 \%$ of the total show 'converging' learning style types, albeit the - just three - 'accommodators' have scored higher in critical thinking, while the prevailing learning style type is the 'assimilating' with a percentage of $52.9 \%$ (tables 4 and 6 ). This may be a reason why student critical thinking scores are low, relative to their studies level. On the other hand, not both dimensions of learning (receiving new information and experience, i.e. Concrete-Abstract dimension and processing of perceived information and experience, i.e. Active-Reflective dimension) show positive correlation with critical thinking skills. Only the second phase AE-RO scores correlate significantly with critical thinking scales. This needs further research, as it seems to be a second explanation of low student critical thinking scores.

\section{CONCLUSION}

In this study we report results regarding learning style improvements and critical thinking abilities of a sample of sixty-eight postgraduate students. This sample has been derived by chance out of two much bigger samples of a research regarding the assessment of student learning styles and critical thinking skills. Results show that students' predominant learning style type is the 'assimilating' one and that students, in a time span ranging from seven to eleven months between first and second phases of the research, have improved their learning style preferences to more balanced ones. This balancing development is clearer if viewed through grouping of students for their learning style types. Students score relatively low in critical thinking skills. These low scores show greater homogeneity if viewed through grouping of students for their learning style types again. Correlating learning style types and critical thinking scales scores results in significant positive correlations between only the one dimension of learning and all critical thinking scales. These results represent two possible explanations for low student critical thinking scores. 


\section{THE WAY FORWARD}

Further research should be carried out to corroborate the results of this study under a quasi-experiment basis. Students should be aware of the importance of their spontaneous participation in such studies, as well as their thoughtful participation when completing the questionnaires. As regards the instructors and program directors, they should pay more attention in designing problem-oriented courses that could lead to enhanced student learning and critical thinking skills development.

\section{ACKNOWLEDGEMENTS} acknowledged.

A very kind facilitating attitude of the instructors of the courses participating in our research is

\section{REFERENCES}

1. Adler, R. W., Whiting, R. H., and K. Wynn-Williams (2004), Student-led and teacher-led case presentations: empirical evidence about learning styles in an accounting course, Accounting Education 13(2), 213-229.

2. Barnes, Barry F., Robert C. Preziosi, and Doreen J. Gooden (2004), An examination of the learning styles of online MBA students and their preferred course delivery methods, New Horizons in Adult Education, 28(2), Spring, pp. 19 - 30.

3. Boyce, G., Williams, S., Kelly A. and Helen Yee, (2001) Fostering deep and elaborative learning and generic (soft) skill development: the strategic use of case studies in accounting education, Accounting Education 10 (1), 37-60.

4. Duff, A., (1997) Validating the learning styles questionnaire and inventory of learning processes in accounting: a research note, Accounting Education 6 (3), 263-272.

5. Facione, P. A., Facione, N. C., Blohm S. W., and Giancarlo, C. A. F., 2002 Updated Edition, The California Critical Thinking Skills Test: Test Manual, Insight Assessment, Millbrae, CA.

6. Giancarlo, C. A. and Facione, P. A., (2001), A look across four years at the disposition toward critical thinking among undergraduate students, The Journal of General Education, Vol. 50, No 1.

7. Heffler, B., (2001), Individual Learning Style and the learning style inventory, Educational studies, Vol. 27 , No 3.

8. Honey, Peter and Alan Mumford, The Learning Styles Helper's Guide, Peter Honey Publications, Maidenhead Berks, 2000 .

9. Kolb, D. A., Experiential Learning: experience as the source of learning and development, Prentice-Hall, Englewood Cliffs, NJ., 1984.

10. _ Facilitator's Guide to Learning, Hay/McBer, 2000.

11. Kreber, Carolin, (1998), The relationships between self-directed learning, critical thinking, and psychological type, and some implications for teaching in higher education, Studies in Higher Education, 23 (1), March, pp. 71 - 86.

12. (2001), Learning Experientially through Case Studies? A Conceptual Analysis, Teaching in Higher Education, Vol. 6, No.2.

13. Loo, R., (2002) The distribution of learning styles and types for hard and soft business majors, Educational Psychology, Vol. 22, No 3.

14. Marriott, Pru, (2002), A longitudinal study of undergraduate accounting students' learning style preferences at two UK universities, Accounting Education, 11(1), 43-62.

15. Nawrocki, David and Christine Nawrocki, (2005), Learning Styles and Portfolio Management, Advances in Financial Education, 3, Spring, pp. $99-110$.

16. Siriopoulos, C. and Pomonis, G., forthcoming, Differences in characteristics of postgraduate students in business education programs: chances and risks of career choice, The Podium of Social Sciences, (Greek language journal), University of Thessaly, Greece.

17. Wessel, J. and Williams, R., (2004), Critical thinking and learning styles of students in a problem-based, Master's entrylevel physical therapy program, Physiotherapy Theory and Practice, 20 (2), pp. 79-89.

18. Whipple, Thomas W. and Christopher Moberg, (2000), How Expectations of Relationships with faculty vary by students' learning styles, Journal of Business Education, Proceedings, issue 1.

19. Womack, Kent, (2001), Core Finance Courses in the Top MBA Programs in 2001, Tuck School of Business at Dartmouth, Working Paper No. 01-07, November. 